\title{
BATIN BÖLGESİ ORGANLARININ MR GÖRÜNTÜLERİNDEN ÇOK AŞAMALI HİYERARŞİK SINIFLAMA İLE BÖLÜTLENMESİ
}

\author{
Eşref SELVí ${ }^{1}$, M. Alper SELVER ${ }^{2}$, Ali Emre KAVUR ${ }^{1}$, Cüneyt GÜZELİş ${ }^{3}$, Oğuz \\ DİCLE ${ }^{4}$ \\ ${ }^{1}$ Dokuz Eylül Üniversitesi, Fen Bilimleri Enstitüsü, Buca, İzmir \\ ${ }^{2}$ Dokuz Eylül Üniversitesi, Mühendislik Fakültesi Elektrik Elektronik Mühendisliği Bölümü, Buca, İzmir \\ ${ }^{3}$ İzmir Ekonomi Üniversitesi, Mühendislik Fakültesi Elektrik Elektronik Mühendisliği Bölümü, İzmir. \\ ${ }^{4}$ Dokuz Eylül Üniversitesi, Tıp Fakültesi Radyoloji Anabilimdalı, Balçova, İzmir \\ esref.selvi@gmail.com, alper.selver@deu.edu.tr, emrekavur@gmail.com, cuneyt.guzelis@izmirekonomi.edu.tr, \\ odicle59@gmail.com
}

(Geliş/Received: 09.01.2015; Kabul/Accepted: 13.07.2015)

ÖZET

T1bbi görüntüleme ile anatomi hakkında ayrıntılı bilgi elde edinilebildiğinden, tanı amaçlı görüntüleme günümüzde birçok açıdan önem kazanmıştır. Görüntüleme cihazları tarafindan sunulan verilerin fazlalığı ve çeşitliliği nedeniyle, tüm veri yerine görüntülerde sadece ilgilenilen dokunun belirlenerek ayrılması (Bölütlenmesi) sağlanabilir. Elcil yöntemler ile bölütleme yorucu, zaman alıcı ve deneyim gerektiren bir işlem olduğundan, otomatik yordamlara gereksinim duyulmaktadır. Geliştirilen yordamların klinik koşullarında kullanılabilmesi içinse yüksek başarıma sahip sonuçlar üretmeleri gerekmektedir. Manyetik Rezonans (MR) görüntülerinden batın bölgesindeki organlarının bölütlenmesi pek çok zorluk içeren bir uygulama alanıdır ve bu konudaki çalışmalar sınırlı sayıdadır. Batın bölgesinde yer alan, karaciğer, böbrekler, dalak, pankreas, safra kesesi gibi organların MR görüntüleri kullanılarak ileri seviye tıbbi analizi ve üç boyutlu incelenmesi pek çok tıbbi prosedür için mecburi olduğundan, bu çalışmada, ilgili organların bölütlenmesinde yukarıda belirtilen zorluklara karşı gürbüz, bölütlenecek organın özellikleri ve organların birbirleriyle olan ilişkilerini (konum vb.) göz önüne alan bir sistem geliştirilmiştir. Geliştirilen sistem farklı MR sekansları ile elde edilen görüntülere uygulanarak elde edilen sonuçlar tartışılmıştır.

Anahtar Kelimeler: Bölütleme, MR, hiyerarşik sınıflama, batın

\section{SEGMENTATION OF ABDOMINAL ORGANS FROM MR IMAGES USING MULTI-LEVEL HIERARCHICAL CLASSIFICATION}

\begin{abstract}
Medical imaging modalities can provide very detailed and informative mappings of the anatomy of a subject. These detailed and informative mappings can be processed to extract the information of interest instead of dealing with whole data (segmentation). Since manual segmentation on each slice is time consuming, tedious and operator dependent, automatic tools and techniques are needed. Segmentation of abdominal organs is a very challenging field of application due to overlapping intensity ranges of the organs, variations in human anatomy and pathology and the number of studies is very limited for Magnetic Resonance (MR), which is a relatively newer and rapidly developing imaging modality. Since it is obligatory to analyze and visualize MR images of abdominal organs (i.e. liver, right/left kidneys, spleen, pancreas, gall bladder) for several medical procedures, the main goal of this paper is to design and develop a segmentation system (method+software), which is robust to the challenges mentioned above, adaptive to the properties of the abdominal organs as well as to the interrelationships of these organs.
\end{abstract}

Keywords: Segmentation, MR, hierarchical classification, abdomen 


\section{GIRIŞ (INTRODUCTION)}

İnsan vücudunun anatomik yapısı, Bilgisayarlı Tomografi (BT), Manyetik Rezonans Görüntüleme (MR) ve İşlevsel Manyetik Rezonans Görüntüleme (fMRI) ile etkin bir biçimde belirlenebilmektedir. Bu tür cihazlardan elde edilen çoklu veri dilimleri, çeşitli görüntüleme teknikleri kullanılarak Üç Boyutlu (3B) görüntülerin oluşturulmasında kullanılmaktadır. Anatomik yapıların yüksek kalitede 3B görüntüleri, modern görüntüleme teknikleri ile sağlanabilmekle birlikte, çok fazla sayıda organın birleşmesinden kaynaklanan karmaşık iç yapı nedeni ile ilgi bölgesinin tek başına ayrıştırılmış bir şekilde görüntülenmesi gerekmektedir. Bu ayrıştırma işlemi tıbbi hacim bölütleme olarak adlandırılır. Elcil yöntemler ile bölütleme yorucu, zaman alıcı ve tecrübe gerektiren bir işlem olduğundan, bilgisayar destekli otomatik bölütleme yordamlarına ihtiyaç duyulmaktadır. Bölütleme yordamlarında, organın veya ilgi-bölgesinin sınırlarını doğru bir şekilde çıkarmak en önemli olgudur. Fakat örnekleme artifaktları, gürültü, düşük kontrast gibi tıbbi cihazlardan kaynaklanan problemler, anatomik yapıların ayırt edilemez ve kopuk olmasina neden olabilmektedirler.

Tıbbi uygulamaların gerektirdiği hassas ölçümler, ayrıntılı analizler ve 3B görüntülemenin yapılabilmesi için, batın bölgesi organlarının kendileri kadar birbirleriyle olan ilişkileri de önem taşıdığından, batın bölgesi organlarını beraber bölütleyen yöntemlere ihtiyaç duyulmaktadır. Batın bölgesi organlarının birlikte bölütlenmesi konusunda BT alanında başarılı çalışmalar olmasına karşın [1-8], görece daha yeni olan ve özellikleri sürekli gelişen Manyetik Rezonans (MR) görüntülerinde batın bölgesi organlarının bölütlenmesinde, organ bazında yapılan çalışmalar ağırlıklıdır. Bu çalışmalar özellikle karaciğer üzerine yoğunlaşmış olup [9-12], böbrekler [13], dalak [14], yağ ve kas dokularının [15] bölütlenmesi ile ilgili çalışmalar bulunmaktadır. MR görüntülerinden beyin dokusunun [16] ve batın bölgesi anevrizmalarının $[17,18]$ bölütlenmesi yaygın çalışma konuları olmasına karşın, batın bölgesi organlarının beraber bölütlenmesi konusundaki çalışmalar sınırlı sayıdadır $[2,19]$.

Batın bölgesindeki organların bölütlenmesi pek çok etken nedeniyle zor bir bölütleme uygulamasıdır. Batın bölgesindeki organların bölütlenmesindeki ilk zorluk, ilgili organların MR görüntülerinde insandan insana gösterdiği şekil, desen, büyüklük, doğrultu ve pozisyon değişiklikleridir. $\mathrm{Bu}$ yüksek değişkenlik şekil tabanl 120], model tabanlı (uzaysal [21], popülasyon tabanlı geometrik [16], rassal [22]), ve atlas tabanlı [23, 24] yöntemlerin başarımlarını sınırlamaktadır. İlave olarak, bu çalışmada kullanılan veri setleri günlük iş akışından alınan standart edinimlerden toplanmıştır. Dolayısıyla, alınan veri setlerinin kesitler arası uzaklık değerleri, organların sunumunda kesitler arası seyreklik olmasina ve buna bağlı olarak ani organ şekli ve boyutu değişimlerine neden olmaktadır.

Batın bölgesindeki organların bölütlenmesindeki ikinci zorluk ise özellikle örtüşen organ yoğunlukları, bazı çekimlerde vücuda verilen opak madde ve MR görüntülerinin çekim süresinden kaynaklanan sınır belirsizlikleri nedeniyle oluşan teknik zorluklardır. Örtüşen organ yoğunlukları, BT görüntülemede daha fazla olmakla birlikte MR görüntülemede de yoğunluk tabanlı (dinamik eşikleme [25], gri-seviye [26], morfoloji [27], ve bunların kombinasyonu ile oluşan teknikler [28]) yöntemlerin başarımını sınırlar. Benzer şekilde, hastaya ait görüntü serisinin edinimi sırasında alınan sinyal yoğunluğundaki sapmalar da aynı veri setinin içerisinde bile aynı dokuda önemli değişiklikler meydana getirebilir.

Vücuda verilen maddenin organ dokularını görüntülerde heterojen hale getirmesi ise desen tabanlı [29] tekniklerin kullanımını, hacimsel olarak $[30,31]$ kullanılsalar bile sinırlar. Ayrıca, etkili yöntemler olan ancak parankima gri seviyesinin homojenliği ve organ sınırlarının belirliliğine dayanan düzey kümeleri (level sets) [32], bölge büyütme [33]",fast marching" [34], aktif kontur [35] gibi yöntemlerin etkin kullanılmasını engellerler.

İlave olarak, farklı MR sekansları fiziksel ve matematiksel ilkelerine bağlı olarak aynı organ için farklı yoğunluk değer aralıkları (intensity range) içeren görüntüler oluşturmaktadır (Şekil 1) ve bu durum yoğunluk odaklı yaklaşımlar için genelgeçer bir gri seviye aralığı belirlemeyi zorlaştırır.

Klinik MR görüntülerinin analizinde, homojen olmayan manyetik alandan, hareketlerden, gürülttülerden ve diğer nedenlerden kaynaklanan zorluklar da yaşanmaktadır. Örneğin, bias alanları MR görüntülemedeki önemli sorunlardan birini oluşturur ve sıklıkla tek bir yüzey bobini tarafindan ortaya çıkarılan çarpımsal bias alanlarından meydana gelir. $\mathrm{Bu}$ alanlar, belirli bölgelerde düşük frekansl1, bölgesel, düzgün koyuluklar oluşturur.

Sinıflayıcı tabanlı teknikler, yukarıda belirtilen yöntemlerin çözemedikleri zorluklarla başa çıkabilen alternatif yöntemlerdir [3, 4, 36-38]. Ancak, yeterli başarımı sağlayabilmeleri için iki noktaya özellikle dikkat edilmesi gerekmektedir. Bunlardan ilki, sınıflayıcı parametrelerinin önceden belirlenmesidir. Yukarıda belirtilen yoğun değişkenlik özelliği nedeniyle, batın bölgesi organlarının bölütlenmesinde, mümkün olan tüm parametreler bölütlenmekte olan veriye bağlı olarak belirlenmelidir. İkinci önemli nokta ise, eğiticili yöntemlerde kullanılan eğitim 
kümesinin oluşturulmasıdır. Sınırlı sayıda eğitim kümesi ile sistemi önceden eğitmenin başarımı sınırladığı bilinmektedir [39]. Bölütlenecek görüntü serisinin bir kısmının eğitim için kullanılması [28] ise, hem kullanıcıya bağımlı hem de klinik ortamda pratik olmayan bir işlem olduğundan yaygınlaşamamıştır. Eğiticisiz yöntemlerin ise yalnızca sınırlı yarar sağladığı ve özellikle organ sınırlarında başarısız olduğu bilimsel literatürde gözlemlenmiştir [40, 41]. $\mathrm{Bu}$ nedenlerle, eğitimi bölütleme işlemine paralel olarak gerçekleştiren uyarlamalı sınıflayıcıların kullanımı başarılı alternatif bir yöntemdir [36].

Sınıflayıcıların başarımında öznitelik uzayının veriyi temsil etme yeteneği büyük önem taşır. Batın bölgesi organları üzerinden pek çok öznitelik çıkarılarak kullanılmıştır ancak bunların hiçbiri tek başına batın bölgesi organlarını saptamada yeterli olmamaktadır. $\mathrm{Bu}$ nedenle, bu özniteliklerin uygun bir şekilde bir arada kullanılması gerekmektedir. En basit yol olarak, bu öznitelikler birleştirilerek tek ve büyük bir öznitelik vektörü oluşturulabilir. Ancak, bu yöntemin sınıflayıcının karmaşıklığını arttırma, işlem yükünü fazlalaştırma ve genelleme yeteneğini azaltma gibi birçok dezavantajı bulunmaktadır . [42, 43].

İkinci bir yöntem, farklı özniteliklerin farklı sınıflayıcılarla beraber kullanılarak işlenmesi yöntemidir [44, 45]. Yaygın olarak kullanılmakta olan bu ikinci yolda önemli olan, en uygun özniteliksınıflayıcı eşleşmelerini yapabilmektir. Farklı uygulama alanlarındaki birçok çalışma, özniteliksınıflayıcı çiftleri kullanmanın avantajlarını göstermiştir [46-51].

$\mathrm{Bu}$ çalışmada batın bölgesinde yer alan organların MR görüntüleri kullanılarak ileri seviye analizi ve detaylı üç boyutlu görüntülemesi için $\mathrm{MR}$ görüntü serilerinin işlenmesindeki zorluklara karşı gürbüz; bölütlenecek organların ayırıcı özellikleri ve organların birbirleriyle olan ilişkilerini göz önüne alan bir sistem geliştirilmiştir. $\mathrm{Bu}$ amaçla, çalışma kapsamında Çok Aşamalı Hiyerarşik Sınıflayıcı (ÇAHS) modeli tasarlanmıştır.

ÇAHS'nin başarımı hassas ölçümlerin yapılabileceği düzeyde artırılmış ve sonuç olarak yarı-otomatik ve uyarlamalı olma özelliklerine sahip bir tıbbi hacim bölütleme yöntemi elde edilmiştir. Makalenin bundan sonraki bölümleri şu şekilde düzenlenmiştir: İkinci bölümde geliştirilen hiyerarşik sınıflama sistemi ve bölütleme yöntemi sunulmuştur. Üçüncü bölüm kullanılan görüntü serileri, MR sekansları özelliklerini ve geliştirilen sistemin uygulanma sonuçlarını sunmaktadır. Bölüm dört ise tartışma ve yorumları içermektedir.
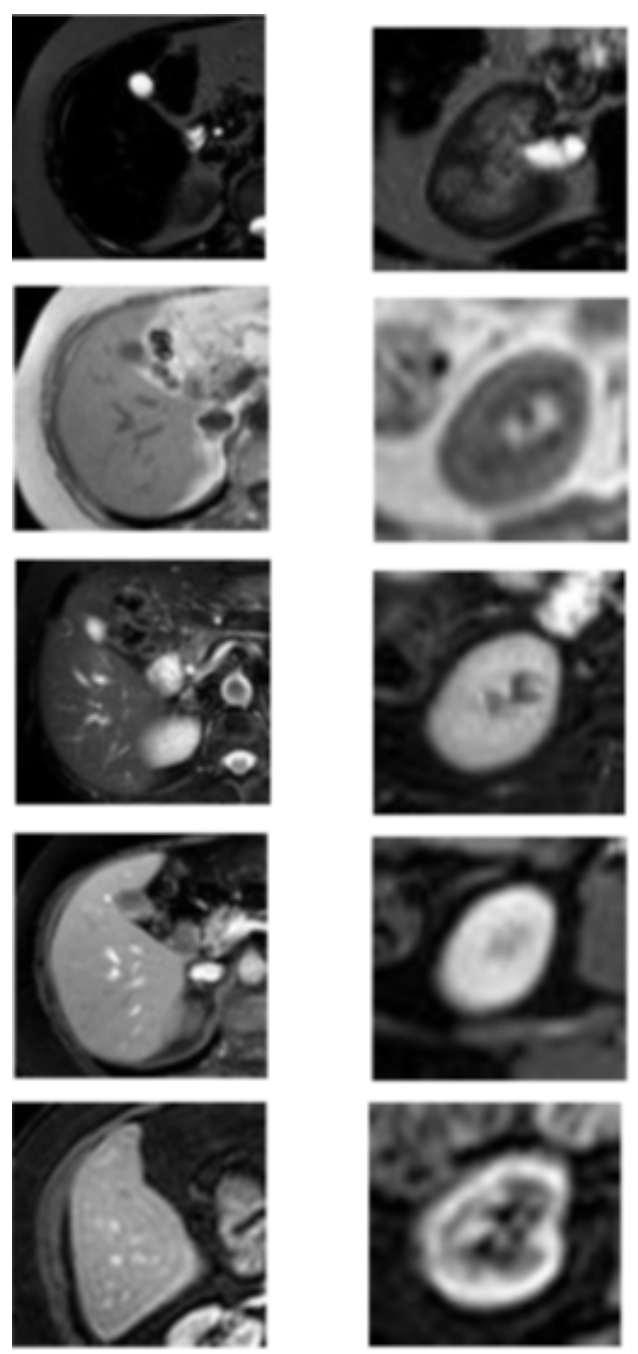

Şekil 1. Farklı MR sekanslarında karaciğer (Sol) ve sağ böbrek (sağ) görüntüleme (üstten alta: SSH, T1DUAL, T2-SPIR, WATS, THRIVE) (Imaging liver (left) and right kidney (right) using various MR sequences (from bottom to top: SSH, T1-DUAL, T2-SPIR, WATS, THRIVE)).

\section{2. ÖZNITELIIKLER VE HIYERARŞIK SINIFLAMA TABANLI BÖLÜTLEME (FEATURES AND HIERARCHICAL CLASSIFICATION BASED SEGMENTATION)}

Batın bölgesi organlarının parankimal ve sınır bilgilerini farklı öznitelikler içerisinde başarılı şekilde temsil edebilme yetenekleri nedeniyle istatistiksel desen öznitelikleri kullanılmıştır. İstatistiksel desen ve tektürelliği temsil edecek özniteliklerin çıkarılmasında Toplam-Fark Histogramları (TFH) ve "Co-occurence" Matris (COM) yöntemleri kullanılabilir. TFH ve COM yöntemlerinin birbirine çok yakın başarım verdiği literatürdeki çalışmalar ile gösterilmiştir. Öte yandan, COM için gerekli bellek miktarı TFH kullanımı için gerekli bellek miktarından çok daha yüksektir. Dolayısıyla, analizler TFH vektörlerinden çıkarılan öznitelikler için gerçekleştirilmiştir. 
TFH ile öznitelik çıkarımı için, KxL'lik bir MR TFH ile öznitelik çıkarımı için, KxL'lik bir MR görüntüsü (y) ele alınırsa, görüntü matrisinin her bir elemanı $\left\{\mathrm{y}_{\mathrm{k}, 1}\right\}, \quad\{\mathrm{k}=1,2, \ldots, \mathrm{K} ; \quad \mathrm{l}=1,2, \ldots ., \mathrm{L}\} \quad$ olarak tanımlanabilir. Ayrıca, bu MR görüntüsündeki bit derinliği $G$ ile ifade edilsin. Bu durumda $2^{\mathrm{G}}=\{1,2, \ldots$, $\mathrm{N}_{\mathrm{G}}$ \} olmak üzere $\mathrm{N}_{\mathrm{G}}$ farklı gri seviye değerimiz olsun. $\left(\mathrm{d}_{1}, \mathrm{~d}_{2}\right)$ mesafesi ile tanımlanmış bir alanı, $\mathrm{y}_{\mathrm{l}}=\mathrm{y}_{\mathrm{k}, 1}$ ve $\mathrm{y}_{2}=\mathrm{y}_{\mathrm{k}+\mathrm{d} 1,1+\mathrm{d} 2}$, olarak tanımlarsak, TFH aşağıdaki şekilde tanımlanır [52];

$\mathrm{t}_{\mathrm{k}, 1}=\mathrm{y}_{\mathrm{k}, 1}+\mathrm{y}_{\mathrm{k}+\mathrm{d} 1,1+\mathrm{d} 2}$

$\mathrm{f}_{\mathrm{k}, 1}=\mathrm{y}_{\mathrm{k}, 1}-\mathrm{y}_{\mathrm{k}+\mathrm{d} 1,1+\mathrm{d} 2}$.

Burada, (1) numaralı denklem toplam histogramı ve (2) numaralı denklem fark histogramı olarak adlandırılır. $\mathrm{Bu}$ vektörler aracılığı ile normalize edilmiş toplam histogramları $\left(\mathrm{P}_{\mathrm{t}}(\mathrm{i})\right)$ ve fark histogramları $\mathrm{P}_{\mathrm{f}}(\mathrm{i})$ olarak adlandırılan $\left[2 \mathrm{xN}_{\mathrm{G}}-1\right]$ boyutlu vektörler şu şekilde hesaplanır;

$\mathrm{P}_{\mathrm{t}}(\mathrm{i})=\mathrm{h}_{\mathrm{t}}(\mathrm{i}) / \mathrm{N}, \quad\left(\mathrm{i}=2, \ldots, 2 \mathrm{~N}_{\mathrm{G}}\right)$,

$\mathrm{P}_{\mathrm{f}}(\mathrm{i})=\mathrm{h}_{\mathrm{f}}(\mathrm{i}) / \mathrm{N}, \quad\left(\mathrm{i}=-\mathrm{N}_{\mathrm{G}}+1, \ldots, \mathrm{N}_{\mathrm{G}}-1\right)$.

Burada, $h_{t}(i)$ ve $h_{f}(i)$ şu şekilde tanımlanmıştır (Card fonksiyonu "Cardinality”'ye karşılık gelmekte olup; ilgili kümenin eleman sayısını ifade etmektedir):

$\mathrm{h}_{\mathrm{t}}(\mathrm{i})=\operatorname{Card}\left\{(\mathrm{k}, 1) \in \mathrm{D}, \mathrm{t}_{\mathrm{k}, \mathrm{l}}=\mathrm{i}\right\}$, $\mathrm{h}_{\mathrm{f}}(\mathrm{i})=\operatorname{Card}\left\{(\mathrm{k}, \mathrm{l}) \in \mathrm{D}, \mathrm{f}_{\mathrm{k}, \mathrm{l}}=\mathrm{i}\right\}$,

$\mathrm{N}=\mathrm{Card}\{\mathrm{D}\}=\sum_{i} \operatorname{ht}(\mathrm{i})=\sum_{j} \mathrm{hf}(\mathrm{i})$.

Uygulamamızda, 16 bitlik görüntüler kullanılması sebebiyle $\mathrm{N}_{\mathrm{G}}=65536$ 'dır. Dolayısıyla, her görüntü için, 2 adet 131071 elemanlı $(2 \times 65536-1=131071)$ vektör, $\mathrm{P}_{\mathrm{t} 1}, \mathrm{P}_{\mathrm{fl}}, \mathrm{P}_{\mathrm{t} 2}, \mathrm{P}_{\mathrm{f} 2}, \mathrm{P}_{\mathrm{t} 3}$, ve $\mathrm{P}_{\mathrm{f} 3}$, elde edilmektedir. Deseni ifade eden bu çok sayıdaki elemanı azaltmak amacıyla, her vektör çifti için 7 öznitelik çıkarılmıştır (Tablo 1).

İstatistiksel özniteliklerin batın bölgesi organlarının farklı özelliklerini temsil etmede başarılı oldukları önceki çalışmalarda BT görüntüleri için gösterilmiştir [9, 53]. İstatistiksel öznitelikler organ parankimasını temsil eden (ortalama, homojenlik, yamukluk, ilinti) ve organ sınırını temsil eden (entropi, kontrast, enerji, varyans) öznitelikleri olarak iki gruba ayrılabilir. Yapılan incelemeler sonucunda parankima temsilinde başarılı bulunan ortalama özniteliklerine ilişkin 2boyutlu örnekler Şekil 2'de sunulmuştur. Diğer özniteliklere ait örnek görüntüler ise Şekil 3'de gösterilmiştir.

Benzer şekilde, organ sınırı temsilinde başarılı bulunan özniteliklere ilişkin 2-boyutlu örnekler Şekil 4'de sunulmuştur. Bu özniteliklerde görülebileceği gibi, farklı öznitelikler, sınırların farklı bileşenlerini taşımaktadır. Bu nedenle özniteliklerin uygun şekilde bir araya getirilerek kullanımı, ÇAHS modelinin başarımında önemli role sahiptir.

Sinıflama tabanlı bölütlemede uygun bir sinıflayıcı mimarisi ve öznitelikler kullanılarak sınıflama başarımını düşürücü etkenlerin etkisinin azaltılması gereklidir. Sinıflama başarımını düşürücü etkenlere örnek olarak i) özniteliklerin karmaşıklığının ve bölütlenecek verinin boyutunun büyüklügüünün yol açacağı genelleme özelliği kaybının engellenmesi, ii) hesap yükü ve işlem miktarının klinik kullanımı zorlaştırması, verilebilir. Bu engelleri aşma amacıyla geliştirilen ÇAHS modeli, çıkarılan özniteliklerin organların yeterli hassasiyette bölütlenmesini sağlayacak şekilde tasarlanmıştır.

Tüm görüntüden çıkarılan öznitelikler kullanılarak batın bölgesi organlarının tek sinıflayıcı ile sınıflanmasında dikkatle ele alınması gereken ve başarımı artırıcı iki önemli nokta bulunmaktadır:

1) Öznitelikler birleştirilerek tek giriş vektörünün oluşturulmasının ardından, her sınıfın (organın) teker teker sinıflanmak üzere aşama aşama bölütleme,

2) Her aşamada hedeflenen organa karşılık gelen verinin sınıflanması, geri kalan verinin bir sonraki

Tablo 1. TFH kullanılarak farklı özniteliklerin hesaplanması (Calculation of features using TFH)

\begin{tabular}{|c|c|c|c|}
\hline Öznitelik & Formül & Öznitelik & Formül \\
\hline Ortalama & $f_{1}=\frac{1}{2} \sum_{i} i \cdot P_{t}(i)$ & Varyans & $f_{2}=\frac{1}{2}\left(\sum_{i}(i-2 \mu)^{2} \cdot P_{t}(i)+\sum_{j} j^{2} \cdot P_{f}(i)\right)$ \\
\hline Enerji & $f_{3}=\sum_{i} P_{t}(i)^{2}+\sum_{j} P_{f}(i)^{2}$ & Illinti & $f_{4}=\frac{1}{2}\left(\sum_{i}(i-2 \mu)^{2} \cdot P_{t}(i)-\sum_{j} j^{2} \cdot P_{f}(i)\right.$ \\
\hline Karşıtlık & $f_{5}=\sum_{j} j^{2} \cdot P_{f}(j)$ & Yamukluk & $f_{6}=\sum_{j} \frac{1}{1+j^{2}} \cdot P_{f}(j)$ \\
\hline
\end{tabular}




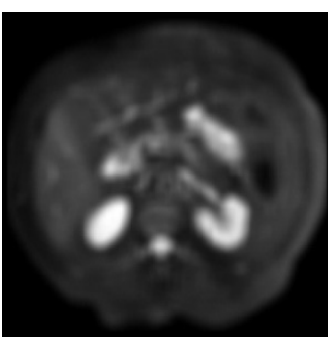

(a)

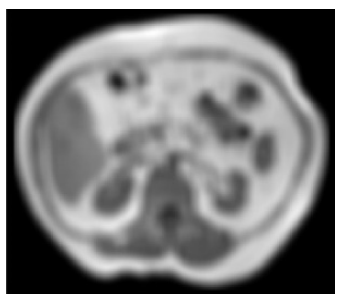

(c)

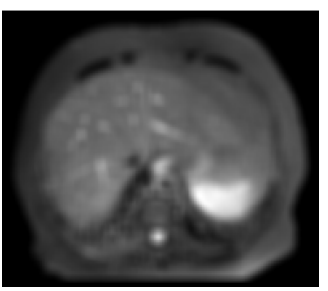

(e)

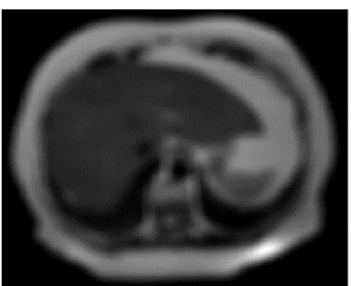

(g)

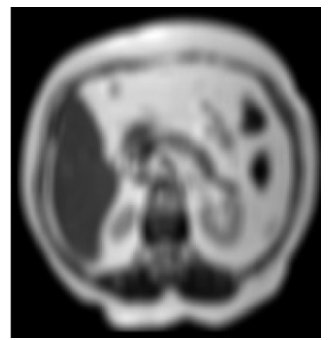

(b)

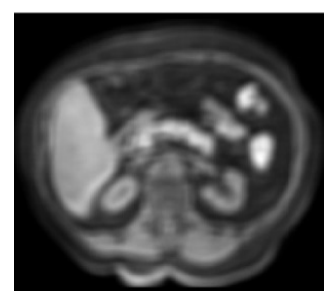

(d)

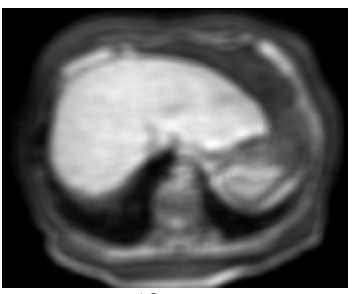

(f)

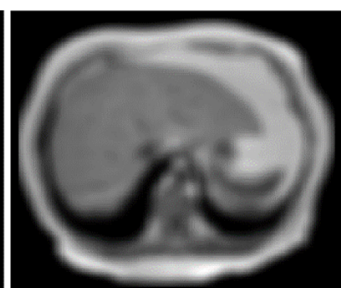

(h)
Şekil 2. Farklı MR sekanslarında benzer anatomik kesitlerin TFH ortalama öznitelikleri (a, e) SPIR, (b, f) SSH, (c, g) T1 DUAL (eşit faz), (d, h) THRIVE (Average feature of the same anatomical structures at various MRI sequences (a, e) SPIR, (b, f) SSH, (c, g) T1 DUAL (in-phase), (d, h) THRIVE)

aşamaya devredilerek verinin kısım kısım sınıflanması ile sistem karmaşıklığının azaltılarak başarımın yükseltilmesi.

Yukarıda belirtilen 1. maddenin genelleştirilmesi ile aşama aşama kullanılmasının başarımı artırdığı stokastik sistemler için gösterilmiştir [42]. Farklı uygulamalarda sunulan sonuçlar $[46,47,48,53]$ da bu sonucu desteklemektedir. Ancak aşamalı kullanımda uygulanacak seçim ve sıralama için genelgeçer bir yöntem bulunmadığından bu konu halen önemli bir araştırma alanıdır. Bu nedenle yukarıda açıklanan 1. ve 2. maddelerin etkin uygulanması için yeni sınıflayıcı tasarımlarına ve modellerine gereksinim duyulmaktadır.

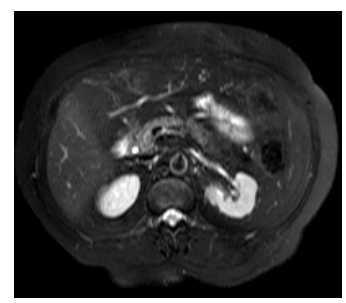

(a)

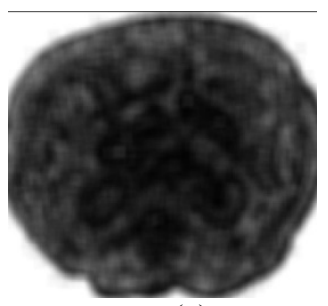

(c)

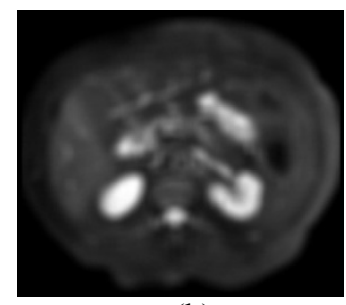

(b)

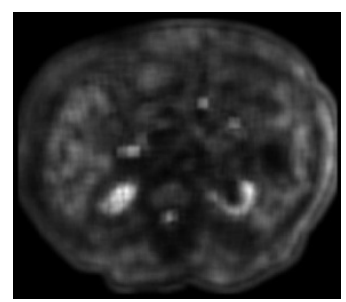

(d)
Şekil 3. SPIR sekansında aynı kesite ait parankima ayırıcı öznitelikler (a) özgün görüntü, (b) TFHortalama, (c) TFH-homojenlik, (d) TFH-yamukluk. (Parenchyma features (a) original image, (b) TFH-average, (c) TFH- homogeneity, (d) TFH-skewness)

Yukarıda anlatılanlar ışı̆̆ında, ÇAHS modeli aşama sayısı (A) kadar sınıflamanın $\left\{l_{i}(\cdot)\right\}_{i=1,2,3 \ldots, A}$ kümesel birleşimi ile $s: R^{D} \rightarrow R$ 'ye bir işlev tanımlar,

$$
y(\boldsymbol{x})=\bigcup_{i=1}^{A} l_{i}(\boldsymbol{x})=l_{1}(\boldsymbol{x}) \bigcup l_{2}(\boldsymbol{x}) \bigcup l_{3}(\boldsymbol{x}) \ldots \bigcup l_{A}(\boldsymbol{x}) .
$$

Burada $i$ her aşamanın indeksini ve $\bigcup$ kümesel birleşim işlemini temsil etmektedir. Bütün aşamalar, $\left\{l_{i}(\cdot)\right\}_{i=1,2,3 \ldots, A}$, birleştirildiğinde, $y(\boldsymbol{x})$ ile gösterilen sınıflama sonucunu oluşturur. Ele alınmakta olan batın bölgesi organlarının bölütlenmesi probleminde her $l_{i}(\cdot)$ bir organı sınıflamakla sorumludur. ÇAHS modelinin genel yapısı Şekil 5.a da gösterilmiştir.

ÇAHS'nin her aşamasında sınıflayıcı olarak çok katmanlı ileri beslemeli ve geri yayılımlı yapay sinir ağı (ÇKA) [54] doğrusal olmayan sınıflamada başarılı olan Levenberg-Marquardt [55] eğitim algoritması ile birlikte kullanılmıştır. Her aşamadaki öznitelik vektör sayısı, o aşamadaki ÇKA'nın girişi sayısını oluşturur. Bu çalışmada aşama sayısı 2 olarak seçilmiş olup, ilk aşama organ parankimasını temsil eden (ortalama, homojenlik, yamukluk, ilinti) ve iknci aşama organ sınırını temsil eden (entropi, kontrast, enerji, varyans) öznitelikleri olarak dörder giriş ile tasarlanmıştır. Ağın gizli katmanında deneysel olarak belirlenen sayıda nöron kullanılmış olup, nöron sayısı belirleme işlem zamanı ve başarım göz önüne alınarak yapılmıştır. Her ÇKA'nın çıkışı tek nörondan (organ ya da organ değil) oluşmaktadır. ÇAHS modelinin sınıflayıcı olarak kullanıldığı yöntemin uygun sonişleme adımlarıyla donatılması ile tıbbi hacim bölütleme yöntemi geliştirilmiştir. Yöntemin klinik kullanıma ve sonuçların uzman etkileşimine açık olması amacıyla kesit kesit ilerlemesi planlanmıştır. 

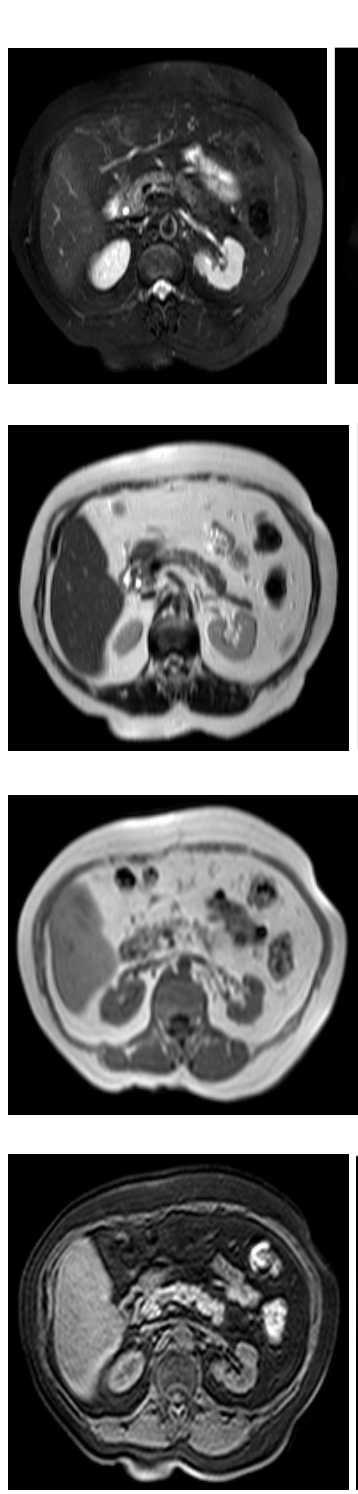

TFH-kontrast
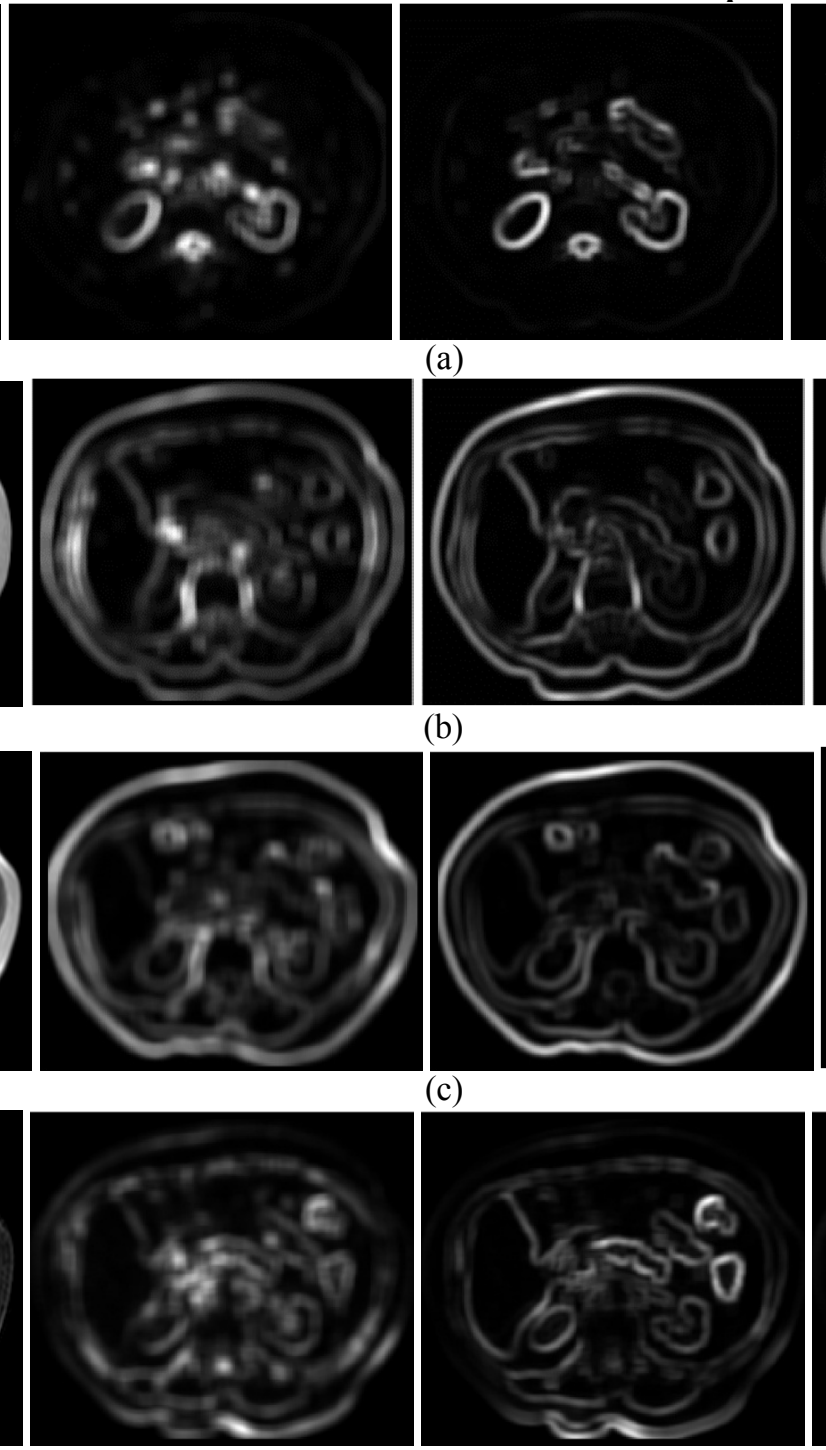

(a)

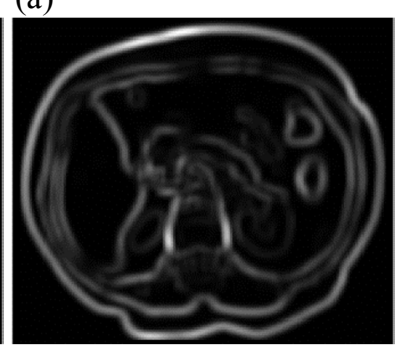

(b)

(c)

TFH-entropi
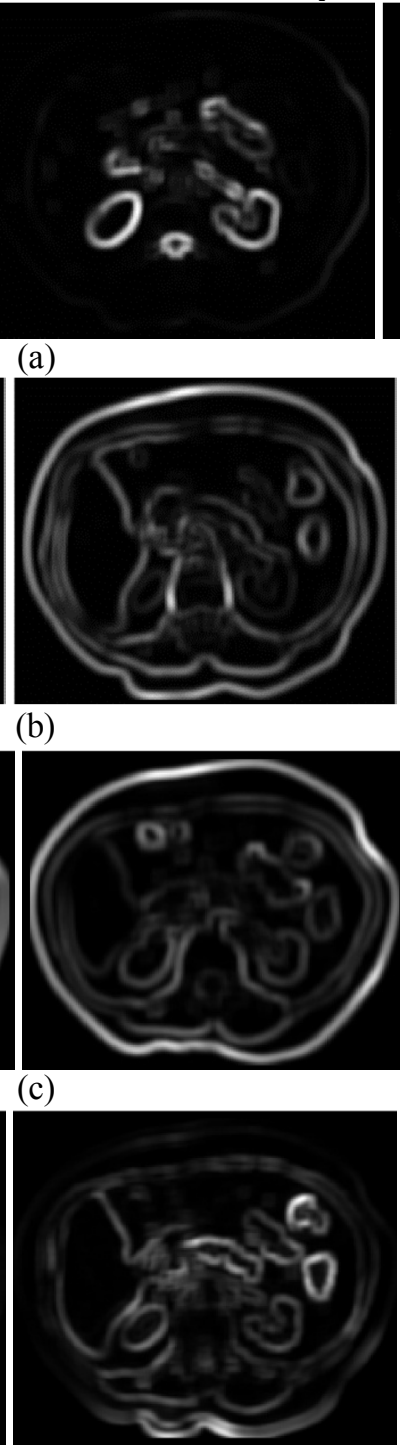

(d)
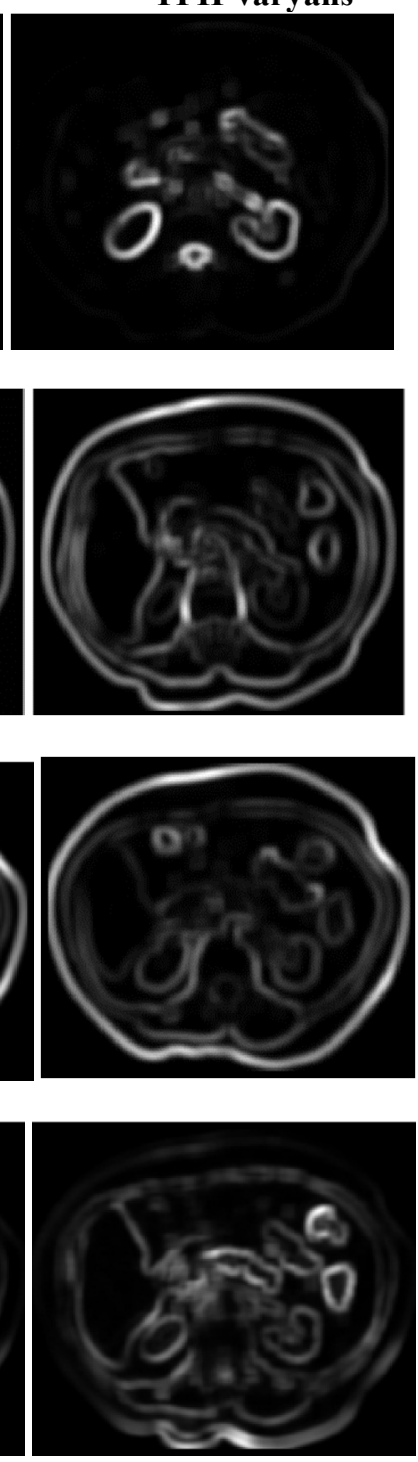

Şekil 4. Farklı MR sekanslarında benzer anatomik kesitlere ait sınır ayırıcı özniteliklerin görüntülenmesi (a) SPIR, (b) SSH TE80, (c) T1 DUAL, (d) THRIVE. Öznitelikler: (soldan sağa) i) özgün görüntü, ii) TFHkontrast, iii) TFH-entropi, iv) TFH-varyans (Boundary features for various MRI sequences (a) SPIR, (b) SSH TE80, (c) T1 DUAL, (d) THRIVE. Features: (from left to right) i) original image, ii) TFH-contrast, iii) TFH-entropy, iv) TFH-variance)

Yarı otomatik olarak tasarlanan bu yöntemde, ilk olarak görüntü serisinden bir Referans Görüntü (RG) uzman tarafindan elcil olarak bölütlenir. İlk adımda RG'den çıkarılan öznitelik vektörleri yine RG'yi bölütlemek üzere eğitilir (Şekil 5.b) ve ÇAHS modelinin başlangıç eğitimi gerçekleştirilmiş olur.

İkinci adımda bir sonraki/önceki görüntüye geçilerek bu görüntüyü bölütlemek için bölütlenmiş RG'den faydalanılacaktır. Sonraki/önceki görüntüden ve RG'den elde edilecek öznitelikler ÇAHS modelinin aşamalarına giriş olarak kullanılır ve sonraki/önceki görüntüdeki organlar bölütlenir (Şekil 5.c). Yeni bölütlenen görüntü, işlem sonunda yeni $R G$ olur ve yordam bu şekilde ilk RG'den başlayıp görüntü serisinin sonuna ve başına doğru devam eder.
Böylelikle tüm görüntü serisi işlenerek bölütleme işlemi tamamlanır. Adım-adım ilerleyen işlemler sırasında ÇAHS'nin her aşamasında yer alan ÇKA'ların eğitiminde durma kriteri ortalama karesel hatanın 0.001 olması ya da 100 iterasyona ulaşılması olarak belirlenmiştir.

Ancak her eğitim öncesinde ÇKA'nın başlangıç ağırlık değerlerinin bir önceki eğitimde bulunan değerler olarak atanması ilk eğitimden sonraki eğitimlerin çok hızlı yakınsamasını ve hedeflenen ortalama karesel hata değerinin yaklaşı 10 iterasyonda bulunmasını sağlamıştır. Belirlenen hata seviyesine oluşan ÇKA, aynı özniteliklerin bir sonraki görüntü için çıkarılmasıyla ardışık görüntünün bölütlemesinde kullanılır. 


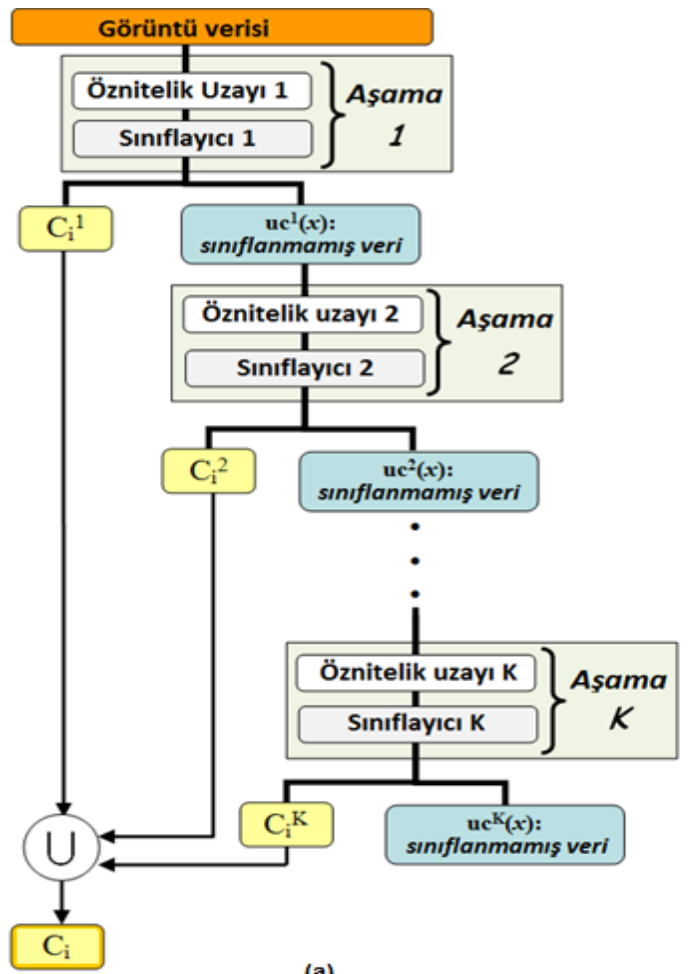

(a)

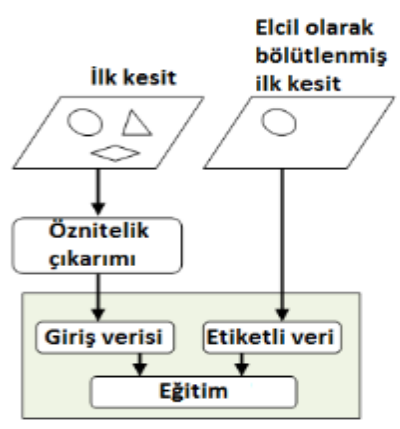

(b)

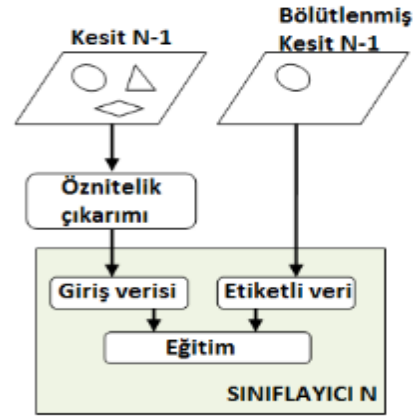

(c)

Şekil 5. (a) ÇAHS modeli (b) ilk sınıflayıcının eğitimi (c) kesit ((a) ÇAHS model, (b) training of the first classifier, (c) segmentation of a slice)

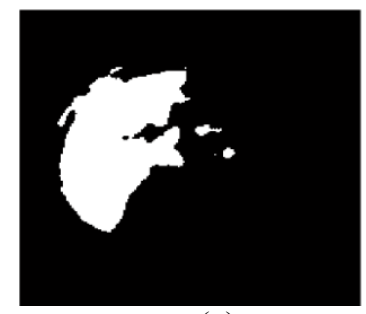

(a)

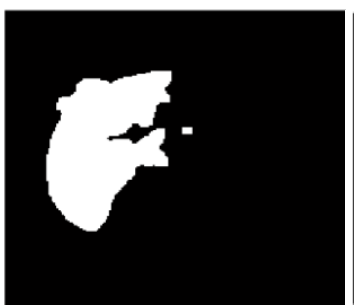

(b)

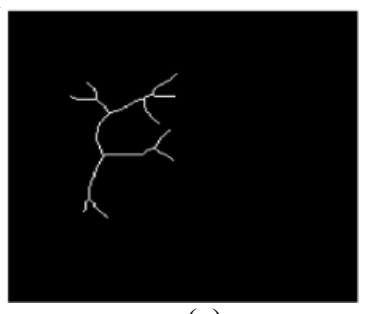

(c)

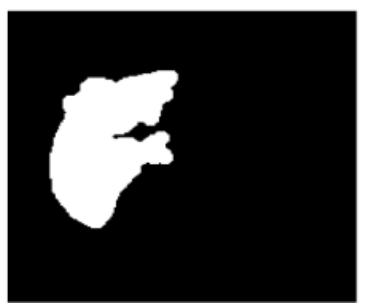

(d)

Şekil 6. (a) Bölütleme sonucu, (b) erozyon ve genişletme sonrası bölütleme sonucu, (c) bir önceki kesite ait sınıflandırma sonucunun iskeletleştirilmesi, (d) b ve c görüntülerinin morfolojik geriçatma uygulanarak işlenmesiyle elde edilen nihai bölütleme sonucu. ((a) Classification result, (b) segmentation result after erosion and dilation, (c) skeletonization of the previous slice, (d) final segmentation result obtained by morphological reconstruction of (b) and (c))

Sinıflama sonucunun bölütleme sonucuna çevrilmesinde bazı son işleme yöntemleri kullanılmıştır. İlk olarak sınıflandırma sonucunda elde edilen görüntüye üç piksel çapında disk şekilli operatör ile sirasıyla morfolojik erozyon ve genişletme işlemi uygulanarak küçük boyuttaki istenmeyen piksel kümeleri elenmiş̧tir (Şekil 6.a-b).

Ancak bazı durumlarda bölütlenen organ dışında diğer organlara ait piksel adacıklarının sonuçlardan ayıklanamadığı gözlemlenmiştir. Bu sorunu gidermek için, elde edilen bölütleme sonucu ile bir önceki kesitten elde edilen sınıflandırma sonucu arasındaki komşuluk ilişkisi, aşağıdaki paragrafta anlatılan ve şekil 6.c'de gösterilen ilave morfolojik işlemler kullanılmıştır.

Bir önceki kesite ait sınıflandırma sonucu elde edilen görüntü önce iskelet dönüşümü aracılığıyla elde edilen iskelet verisi, bölütleme sonucuna ait görüntü ile kesişim işlemine tabi tutulmuştur. Elde edilen yeni iskelet görüntüsü (Şekil 6.c) ve bölütleme sonucu (Şekil 6.b) verileri, morfolojik görüntü geriçatma (image reconstruction) işlemine tabi tutulup sınıflandırma sonucu elde edilmiştir. $\mathrm{Bu}$ sayede bir önceki sınıflandırma sonucu ile komşuluk ilişkisi olmayan pikseller ayırt edilebilmiştir (Şekil 6.d).

\section{UYGULAMA VE SONUÇLAR (APPLICATION AND RESULTS)}

Rutin olarak yapılan radyolojik batın bölgesi incelemelerinde, tanı koymada sağladıkları ayırıcı bilgiler nedeniyle farklı MR sekanslarına ait görüntü verileri kullanılmaktadır. Bu çalışmada da, kullanım yaygınlıkları değerlendirilerek 4 farklı MR sekansına ait görüntülerin bölütleme amaciyla kullanımı gerçekleştirilmiştir. $\mathrm{Bu}$ sekanslar Philips Intera 1.5 Tesla cihazı ile elde edilen T2 SPIR, T1 DUAL, SSH ve THRIVE/WATS sekanslarıdır. MR sekanslarının isimlendirilmesi ve içeriği cihazı üreten firmaya göre 
farklılık gösterebildiğinden, seçilen MR sekanslarına ait özet bilgiler aşağıda verilmiştir. Ayrıca batın bölgesinden elde edilen iki kesite ait farklı sekans görüntüleri Şekil 7'de sunulmuştur.

T2 SPIR “Spectral Presaturation Inversion Recovery" sekansı hibrid bir görüntüleme yöntemi ve öncelikle yağ protonlarının seçici olarak baskılandığı T2 ağırlıklı bir sekanstır. Karaciğer parankiması yağ içeriğinin baskılanması ile çok daha iyi bir şekilde izlenir. T2 ağırlığı nedeniyle organ içinde seyreden damarların izlenebilmesi mümkün olur. Karaciğer çevresinde yer alan yağ dokusunun baskılanması ile karaciğer sınırları ortaya çıkar. İlişik organlardan olan safra kesesi, on iki parmak bağırsak içeriği, pankreas ve sağ böbrek karaciğerden kolay ayrilabilir hale gelir. Sekansın harekete duyarlılığı da düşüktür.

T1 DUAL sekansı, yağ ve su protonlarının farklı T1 zamanlarının olmasından yola çıkarak, uyarılan protonların eski konumlarına dönerken aynı ve birbirine zit yönde oldukları konumlarda sinyal bilgisi alınmasına dayanan bir yağ baskılama sekansıdır. Su ve yağ protonlarının aynı yönde oldukları ve zıt yönde oldukları yankı süreleri belirlenerek sinyal alındığında, out phase görüntüde su ve yağ protonlarının sinyal frekans birbirinden çıkarılmış olacağından yağ baskılaması gerçekleşmiş olur. $\mathrm{Bu}$ sekans daha çok küçük ve hücre içi yağ baskılandığından kitlelerdeki yağ içeriğini anlamada çok yarar sağlar. T1 ağırlıklı bir sekans olduğundan, normalde T1 ağırlıklı serilerde hiperintens görünen ve baskılamadan etkilenmeyecek olan karaciğerdeki yağlanma düzeyi ile ilgili bir fikir sağlar. Ters faz görüntülerde, organ sinırlarında yağ ve su proton miktarı aniden değiştiğinden, bu protonlardan gelen sinyalin eşit olması ve birbirinden çıktığında sinyalsiz bir ortam oluşması nedeniyle organ konturları siyah bir çizgi olarak gözlenir. Bu durum sınır belirleme algoritmaları için de kullanılmaktadır.

SSH sekansı adını "Single shot" ifadesinin kısaltılmış halinden alır. Diyafram, bağırsak gazı ve damar kaynaklı hareketlerin sorun oluşturduğu batın incelemelerinde kısa sürede incelemeye olanak veren sekanslardır. Durağan sıvıların çok iyi incelenebildiği bu sekanslar sayesinde safra yolları kolaylıkla incelenebilmektedir.

THRIVE sekansı karaciğerde bilinen bir lezyonun kontrast maddeye cevabını anlamak üzere, ince kesitler ile karaciğeri kısa sürelerle ardışık olarak tarayan hızlı görüntüleme sekansıdır. Görüntü kalitesinden çok kontrast maddenin sağladığ artışının gözlemini sağlayan bir sekanstır. 3-4 saniyede 500'e yakın kesit alınabilmektedir.

WATS (WATer Selective) yüksek çözünürlüklü, T1ağırlıklı bir yağ baskılama sekansıdır. Bu sekansta da
THRIVE'da olduğu gibi kontrast madde takibi ardışık MR çekimi ile yapılır.

Çalışmadaki MR serilerinin özellikleri, sekans çeşitleri, piksel aralıkları, kesit kalınlıkları ve seri sayısı Tablo 2'de sunulmuştur. Çalışmada 21 farklı hastadan elde edilen MR görüntüleri ve sekansları kullanılmıştır. T2SPIR, SSH ve T1DUAL sekansları bütün seriler için ortak olup, yirmi hasta için ek olarak THRIVE (yedi) ya da WATS (on üç) sekansı kullanılmıştır.

Çalışmada kullanılan MR görüntü serilerinde yer alan organları, konusunda 20 yılın üzerinde deneyime sahip bir radyolog tarafindan elcil olarak bölütlenerek referans görüntü serileri oluşturulmuştur. Özniteliklerin oluşturulması sırasında kullanılan ve pikseller arasında $(\mathrm{d} 1, \mathrm{~d} 2)$ mesafesi ile tanımlanan komşuluk, en yakın 8 yönlü komşuluk olarak seçilmiştir. Ancak, karşı yönlü komşuluklar aynı TFH'leri ürettikleri için 4 yönlü komşuluk kullanmak yeterli olmuştur.

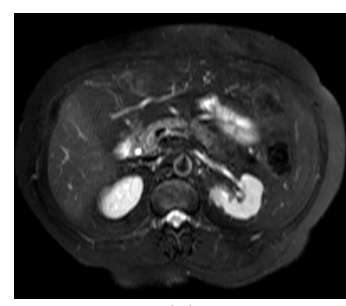

(a)

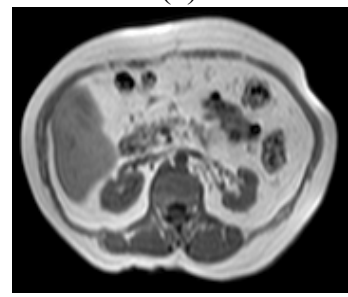

(c)

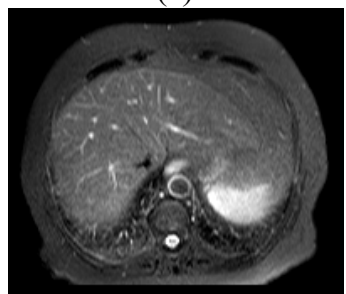

(e)

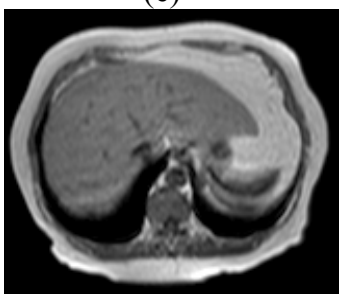

(g)

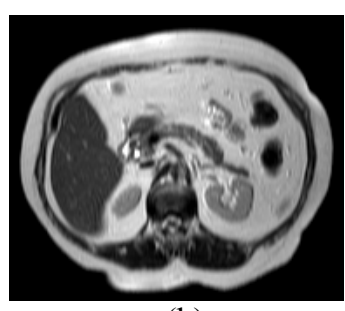

(b)

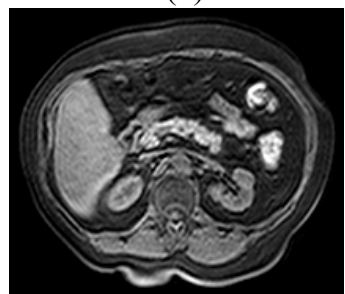

(d)

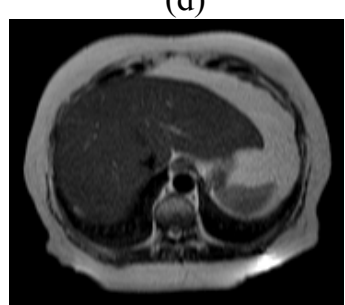

(f)

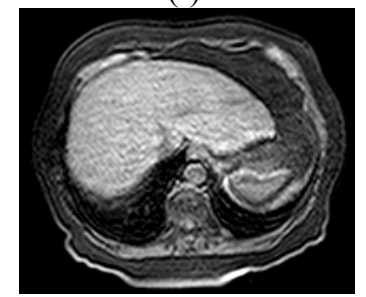

(h)
Şekil 7. Farklı MR sekanslarında benzer anatomik kesitlerin görüntü örnekleri (a,e) T2 SPIR, (b, f) SSH (c, g) T1 DUAL (aynı faz), (d,h) THRIVE. (Illustration of similar anatomical structures at different MRI sequences $(\mathrm{a}, \mathrm{e}) \mathrm{T} 2$ SPIR, (b, f) SSH (c, g) T1 DUAL (aynı faz), (d,h) THRIVE) 
Bölütleme sonuçlarını değerlendirmek için kullanılan ilk metrik Hacimsel Hata Oranı (HHO) ölçümüdür. HHO, Algoritma ile Bölütlenen Hacim (ABH) ile Elcil Bölütlenen Alan (EBH) arasındaki farka dayalı bir değerlendirme tekniğidir. Küme işlemleri kullanılarak $\mathrm{ABH}$ ve $\mathrm{EBH}$ arasında birleşim hacmi, $\mathrm{BH}=\mathrm{ABH} \mathrm{EBH}$ ve kesişim hacmi, $\mathrm{KH}=\mathrm{ABH} \mathrm{EBH}$, tanımlandığında, HHO aşağıdaki şekilde hesaplanır:

$$
H H O=\frac{B H-K H}{E B H} \times 100 \%
$$

Sonuçların değerlendirilmesinde, hacim değerlerindeki farklılıklar kadar elde edilen bölütleme sonucunun şekilsel özellikleri de önem taşır. Bu amaçla, simetrik yüzey mesafesi (SYM) olarak bilinen ve yaygın olarak kullanılan üç metrik de değerlendirmeler için hesaplanmıştır. [55]. SYM metrikleri, üç boyutlu bir nesnenin yüzey voksellerini kullanarak bölütlenmiş 3-boyutlu organın referans organ ile karşılaştırılmasını sağlar. Burada yüzey vokseli olarak tanımlanan vokseller, nesnenin 18 komşuluğunda nesneye ait olmayan en az bir voksel olmasına göre belirlenir. Referans organdaki $\left(V_{R}\right)$ her yüzey vokseli için bölütlenen organdaki yüzey voksellerine olan mesafe öklit mesafe Metriğine göre hesaplanır. Ölçülen mesafeler arasında en küçüğü en yakın komşuluk kuralına göre belirlenir. Eğer bölütlenmiş organa $\left(V_{S}\right)$ ait yüzey vokselleri $S\left(V_{S}\right)$ ile ifade edilirse, referans organ $\left(V_{R}\right)$ üzerindeki herhangi bir vokselin $\left(\mathrm{V}_{\mathrm{r}}\right) \mathrm{S}\left(\mathrm{V}_{\mathrm{S}}\right)$ 'e olan mesafesi

$d\left(v_{r}, S\left(V_{S}\right)\right)=\min _{\substack{v \in S\left(V_{R}\right) \\ \forall q \in S\left(V_{S}\right)}}\left(\left\|v_{r}-q\right\|\right)$

formülü ile hesaplanabilir. Simetri özelliğinin sağlanması için aynı işlem $\mathrm{V}_{\mathrm{R}}$ 'ye ait yüzey vokselleri için de tekrar edilir $\left(d\left(v_{s}, S\left(V_{R}\right)\right)\right)$. Sonrasında, üç ayrı SYM metriği olan Ortalama SYM (OSYM) (9), Etkin değer SYM (ESYM) (10), ve Maksimum SYM (MSYM) (11) hesaplanır (Burada, $\left|S\left(V_{S}\right)\right|$ ve $\left|S\left(V_{R}\right)\right|$ sirasıyla $V_{S}$ ve $V_{R}$ da yer alan voksel sayısını verir).

$$
\begin{array}{r}
O S Y M=\sum_{v_{r} \in S\left(V_{R}\right)} d\left(v_{r}, S\left(V_{S}\right)\right)+\sum_{v_{s} \in S\left(V_{S}\right)} d\left(v_{s}, S\left(V_{R}\right)\right) /\left(\left|S\left(V_{S}\right)\right|+\left|S\left(V_{R}\right)\right|\right) \quad(m m) \\
E S Y M=\sqrt{\sum_{v_{r} \in S\left(V_{R}\right)} d^{2}\left(v_{r}, S\left(V_{S}\right)\right)+\sum_{v_{s} \in S\left(V_{S}\right)} d^{2}\left(v_{s}, S\left(V_{R}\right)\right) /\left(\left|S\left(V_{S}\right)\right|+\left|S\left(V_{R}\right)\right|\right)(m m)} \\
M S Y M\left(V_{R}, V_{S}\right)=\max \left\{\max _{v_{r} \in S\left(V_{R}\right)}\left\{d\left(v_{r}, S\left(V_{S}\right)\right)\right\}, \max _{v_{s} \in S\left(V_{S}\right)}\left\{d\left(v_{s}, S\left(V_{R}\right)\right)\right\}\right\}(m m)
\end{array}
$$

\begin{tabular}{|c|c|c|c|c|c|c|c|c|c|}
\hline \multirow[b]{2}{*}{ MR Sekansı } & \multirow[b]{2}{*}{ Ölçüt } & \multicolumn{4}{|c|}{ Karaciğer } & \multicolumn{4}{|c|}{ Dalak } \\
\hline & & $\begin{array}{c}\text { HHO } \\
(\%)\end{array}$ & $\begin{array}{c}\text { OSYM } \\
\text { (mm) }\end{array}$ & \begin{tabular}{|c|} 
ESYM \\
$(\mathrm{mm})$
\end{tabular} & $\begin{array}{c}\text { MSYM } \\
(\mathbf{m m})\end{array}$ & $\begin{array}{c}\text { HHO } \\
(\%)\end{array}$ & $\begin{array}{c}\text { OSYM } \\
\text { (mm) }\end{array}$ & \begin{tabular}{|c|} 
ESYM \\
$(\mathbf{m m})$
\end{tabular} & $\begin{array}{c}\text { MSYM } \\
(\mathbf{m m})\end{array}$ \\
\hline \multirow{2}{*}{$\begin{array}{c}\text { T2 } \\
\text { SPIR }\end{array}$} & Ortalama & 43,50 & 2,41 & 4,10 & 25,65 & 33,29 & 1,81 & 3,49 & 30,66 \\
\hline & Std. Sapma & 20,77 & 0,95 & 1,76 & 8,88 & 7,58 & 0,85 & 2,86 & 31,96 \\
\hline \multirow{2}{*}{$\begin{array}{l}\text { T1 DUAL } \\
\text { (aynı faz) }\end{array}$} & Ortalama & 28,29 & 1,68 & 2,61 & 17,27 & 39,13 & 2,30 & 3,85 & 37,39 \\
\hline & Std. Sapma & 9,28 & 0,54 & 1,15 & 6,95 & 17,52 & 1,27 & 2,11 & 30,18 \\
\hline \multirow{2}{*}{$\begin{array}{l}\text { T1 DUAL (ters } \\
\text { faz) }\end{array}$} & Ortalama & 26,00 & 1,61 & 2,52 & 16,97 & 42,19 & 2,59 & 4,39 & 39,46 \\
\hline & Std. Sapma & 5,66 & 0,30 & 0,85 & 6,54 & 16,21 & 1,38 & 2,29 & 31,03 \\
\hline \multirow{2}{*}{$\begin{array}{c}\text { THRIVE - } \\
\text { WATS }\end{array}$} & Ortalama & 32,86 & 2,69 & 4,23 & 23,34 & - & - & - & - \\
\hline & Std. Sapma & 23,10 & 3,17 & 5,09 & 15,26 & - & - & - & - \\
\hline
\end{tabular}

Tablo 2. MR serileri ve özellikleri. (MRI series and their properties)

\begin{tabular}{|c|c|c|c|c|c|c|c|c|c|c|}
\hline \multirow{2}{*}{ MR Sekans } & \multirow{2}{*}{$\begin{array}{c}\text { Seri } \\
\text { Sayısı }\end{array}$} & \multicolumn{3}{|c|}{ Kesit Kalınlığ $1(\mathrm{~mm})$} & \multicolumn{3}{c|}{$\mathrm{x}-\mathrm{y}$ aralığ $(\mathrm{mm})$} & \multicolumn{3}{c|}{ Kesit Sayıs1 } \\
\cline { 3 - 12 } & En çok & En az & Ort. & En çok & En az & Ort. & En çok & En az & Ort. \\
\hline T2 SPIR & 21 & 7,7 & 9 & 8,6 & 1,36 & 1,89 & 1,53 & 26 & 36 & 30 \\
\hline T1 DUAL & 21 & 5,5 & 9 & 7,84 & 1,44 & 1,89 & 1,61 & 26 & 50 & 32,8 \\
\hline THRIVE & 7 & 2,5 & 2,5 & 2,5 & 1,56 & 1,97 & 1,67 & 80 & 110 & 92,9 \\
\hline WATS & 13 & 5,5 & 9 & 7,9 & 1,36 & 1,67 & 1,43 & 26 & 40 & 30,6 \\
\hline SSH & 21 & 5,5 & 9 & 8,1 & 1.34 & 1,82 & 1,56 & 25 & 50 & 32,2 \\
\hline
\end{tabular}

Tablo 3. Karaciğer ve dalak bölütleme sonuçlarının değerlendirilmesi (Evaluation of liver and spleen segmentation) 
Tablo 4. Sağ ve sol böbrek bölütleme sonuçlarının değerlendirilmesi (Evaluation of right/left kidney segmentation)

\begin{tabular}{|c|c|c|c|c|c|c|c|c|c|}
\hline \multirow[b]{2}{*}{ MR Sekansı } & \multirow[b]{2}{*}{ Ölçüit } & \multicolumn{4}{|c|}{ Sağ Böbrek } & \multicolumn{4}{|c|}{ Sol Böbrek } \\
\hline & & $\begin{array}{c}\text { HHO } \\
(\%)\end{array}$ & $\begin{array}{c}\text { OSYM } \\
(\mathbf{m m})\end{array}$ & $\begin{array}{l}\text { ESYM } \\
(\mathbf{m m})\end{array}$ & $\begin{array}{c}\text { MSYM } \\
\text { (mm) }\end{array}$ & $\begin{array}{c}\text { HHO } \\
(\%)\end{array}$ & $\begin{array}{c}\text { OSYM } \\
\text { (mm) }\end{array}$ & $\begin{array}{c}\text { ESYM } \\
(\mathbf{m m})\end{array}$ & $\begin{array}{c}\text { MSYM } \\
\text { (mm) }\end{array}$ \\
\hline \multirow{2}{*}{ T2 SPIR } & Ortalama & 32,08 & 1,34 & 1,91 & 8,59 & 37,70 & 2,61 & 3,91 & 12,63 \\
\hline & Std. Sapma & 10,42 & 0,49 & 0,90 & 4,00 & 19,18 & 4,56 & 7,41 & 16,87 \\
\hline \multirow{2}{*}{$\begin{array}{l}\text { T1 DUAL } \\
\text { (aynı faz) }\end{array}$} & Ortalama & 50,48 & 2,54 & 3,68 & 13,74 & 75,06 & 3,30 & 4,87 & 16,96 \\
\hline & Std. Sapma & 20,98 & 1,28 & 2,39 & 9,07 & 73,84 & 2,91 & 4,25 & 12,69 \\
\hline \multirow{2}{*}{$\begin{array}{l}\text { T1 DUAL } \\
\text { (ters faz) }\end{array}$} & Ortalama & 56,82 & 2,62 & 3,81 & 14,17 & 63,67 & 4,01 & 5,36 & 16,36 \\
\hline & Std. Sapma & 31,31 & 1,31 & 2,12 & 8,72 & 27,61 & 2,53 & 2,84 & 5,23 \\
\hline
\end{tabular}

Tablo 5. Karaciğer bölütleme sonuçlarının kombinasyonlarının değerlendirilmesi (Evaluation of combining liver segmentation results)

\begin{tabular}{|c|c|c|c|c|c|}
\hline \multirow[b]{2}{*}{ MR Sekansı } & \multirow[b]{2}{*}{ Ölçüt } & \multicolumn{4}{|c|}{ Karaciğer } \\
\hline & & $\begin{array}{c}\text { HHO } \\
(\%)\end{array}$ & $\begin{array}{c}\text { OSYM } \\
(\mathbf{m m})\end{array}$ & $\begin{array}{c}\text { ESYM } \\
(\mathrm{mm})\end{array}$ & $\begin{array}{c}\text { MSYM } \\
\text { (mm) }\end{array}$ \\
\hline \multirow{2}{*}{$\begin{array}{c}\text { T1 DUAL (Aynı Faz)+ } \\
\text { T2 SPIR + } \\
\text { THRIVE/WATS }\end{array}$} & Ortalama & 38,25 & 2,70 & 4,03 & 22,61 \\
\hline & Std. Sapma & 6,79 & 0,48 & 1,05 & 7,12 \\
\hline \multirow{2}{*}{$\begin{array}{c}\text { T1 DUAL (Aynı Faz)+ } \\
\text { T1 DUAL (Ters Faz)+ } \\
\text { T2 SPIR + } \\
\text { THRIVE/WATS }\end{array}$} & Ortalama & 38,55 & 2,62 & 3,88 & 21,77 \\
\hline & Std. Sapma & 6,88 & 0,52 & 1,14 & 7,72 \\
\hline \multirow{2}{*}{$\begin{array}{c}\text { T1 DUAL (Aynı Faz)+ } \\
\text { T1 DUAL (Ters Faz)+ } \\
\text { THRIVE/WATS }\end{array}$} & Ortalama & 38,44 & 2,58 & 3,81 & 21,13 \\
\hline & Std. Sapma & 7,04 & 0,59 & 1,22 & 7,80 \\
\hline
\end{tabular}

Tablo 6. Sağ böbrek bölütleme sonuçlarının kombinasyonlarının değerlendirilmesi (Evaluation of combining right kidney segmentation results)

\begin{tabular}{|c|c|c|c|c|c|}
\hline \multirow[b]{2}{*}{ MR Sekansı } & \multirow[b]{2}{*}{ Ölçüt } & \multicolumn{4}{|c|}{ Să̆ böbrek } \\
\hline & & $\begin{array}{c}\text { HHO } \\
(\%)\end{array}$ & $\begin{array}{c}\text { OSYM } \\
(\mathrm{mm})\end{array}$ & $\begin{array}{l}\text { ESYM } \\
(\mathrm{mm})\end{array}$ & $\begin{array}{c}\text { MSYM } \\
(\mathrm{mm})\end{array}$ \\
\hline \multirow{2}{*}{$\begin{array}{c}\text { T1 DUAL } \underset{\text { SPIR }}{(\text { Aynı Faz) }}+\mathrm{T} 2 \\
\text { TPI }\end{array}$} & Ortalama & 58,31 & 2,80 & 3,58 & 10,86 \\
\hline & Std. Sapma & 21,72 & 1,14 & 1,30 & 3,27 \\
\hline \multirow{2}{*}{$\begin{array}{c}\text { T1 DUAL }(\text { Ters Faz) }+ \text { T2 } \\
\text { SPIR }\end{array}$} & Ortalama & 57,00 & 2,78 & 3,55 & 10,81 \\
\hline & Std. Sapma & 15,41 & 1,07 & 1,24 & 3,14 \\
\hline \multirow{2}{*}{$\begin{array}{c}\text { T1 DUAL (Aynı Faz) }+ \text { T1 } \\
\text { DUAL (Ters Faz) }+ \\
\text { T2SPIR }\end{array}$} & Ortalama & 55,66 & 2,81 & 3,60 & 11,08 \\
\hline & Std. Sapma & 12,89 & 1,09 & 1,28 & 3,41 \\
\hline
\end{tabular}

Anlatılan metriklerin bölütleme sonuçlarını değerlendirme amaciyla kullanılması sonucu elde edilen değerler her organ için sirasiyla Tablo 3 (karaciğer-dalak) ve Tablo 4 (sağ ve sol böbrekler)'de sunulmuştur. Örnek sonuçlar ise Şekil 8'de verilmiştir.

Literatürdeki benzer çalışmalar ile karşılaştırıldığında elde edilen sonuçların özellikle OSYM, ESYM ve MSYM değerlerinde başarılı olduğu görülmektedir. Rutin klinik kullanımdan toplanan görüntü serilerinin zorlukları göz önüne alındığında, yakalanan başarının klinik kullanım için uygunluğu görülmektedir.
Tablo 3'de doldurulmamış olan değerler ilgili MR sekansı ve hasta görüntü serisindeki bir problem (artefakt vb.) nedeniyle bölütlemenin hedeflenen hassasiyet ve başarımın çok altında kalması nedeniyle konulmuştur. $\mathrm{Bu}$ durumu çözmek amaciyla sonraki paragrafta anlatılan füzyon yöntemi kullanılmıştır. Aynı hastaya ait farklı MR sekanslardan elde edilen görüntü serisi kaliteleri farklılık gösterebilmektedir. Bunun nedeni farklı sekansların ardışıl olarak çekilmesidir. $\mathrm{Bu}$ nedenle, örneğin, A sekansındaki görüntü serisi harekete bağlı artefakt ve bozulmalardan etkilenmezken, B sekansındaki görüntü serisi hareket nedeniyle sorunlu hale gelmiş 
olabilir. Bu özellik göz önüne alındığında, farklı sekanslardaki görüntü serilerinin uzaysal farklılıklarının belirli sinırların altında kaldığı durumlarda [54], çoğunluk oylaması (majority voting) ile bölütleme sonuçlarının füzyonu gerçekleştirilmiştir. Elde edilen sonuçlar, Tablo 5 ve 6'da sunulmuştur.

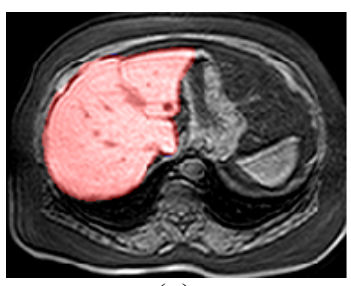

(a)

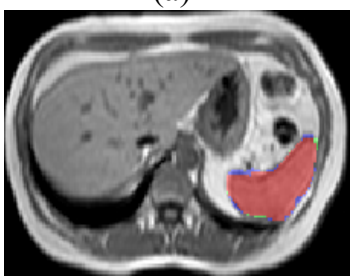

(c)

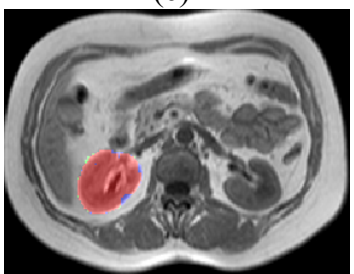

(e)

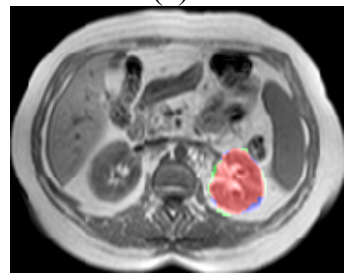

(g)

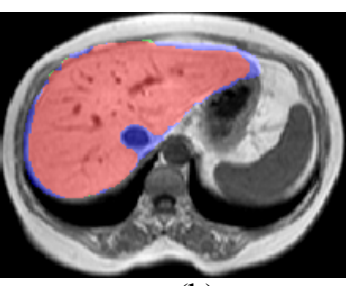

(b)

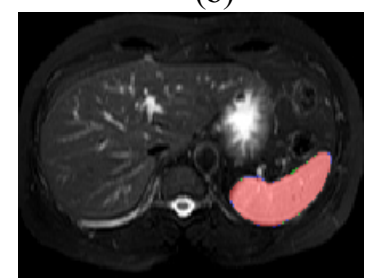

(d)

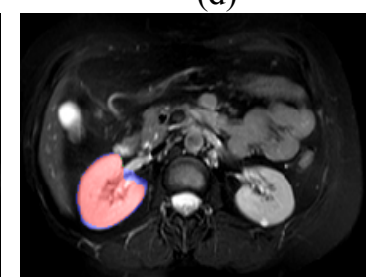

(f)

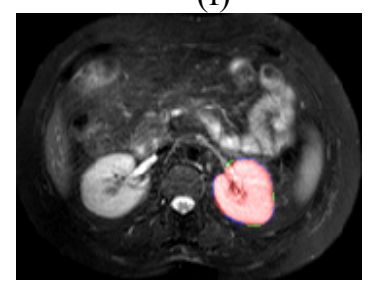

(h)
Şekil 8. Bölütleme sonuç örnekleri: (a) Karaciğer T1 DUAL, b) Karaciğer SPIR, c) Dalak SPIR, d) Dalak SSH, e) Sağ böbrek THRIVE, f) Sağ böbrek SPIR, g) Sol böbrek T1 DUAL, h) Sol böbrek SPIR. (Examples for segmentation results (a) Liver T1 DUAL, b) Liver SPIR, c) Spleen SPIR, d) Spleen SSH, e) Right kidney THRIVE, f) Right kidney SPIR, g) Left kidney T1 DUAL, h) Left kidney SPIR)

\section{SONUÇLAR (CONCLUSIONS)}

MR görüntülerinde veri dilimlerinden batın bölgesi organlarının otomatik olarak bölütlenmesi, görüntü çekimini etkileyen faktörler, insan anatomisinin batın bölgesindeki değişkenliği, olası patalojiler gibi birçok etken nedeniyle çok zordur. Her kesitte batın bölgesi organlarının büyüklük ve şekillerinin değişmesinin yanında organları çevreleyen organlar da değişmektedir.

Ayrıca, komşu organların gri seviye değerlerinin birbirlerine çok yakın olabilmesi, batın bölgesi organlarının farklı kişilerde çok farklı şekillere sahip olabilmesi, bazı çekimler sırasında damarlara verilen opak maddenin farklı organların farklı derecelerde parlaklaşmasına sebep olması gibi nedenler bölütlemeyi zorlaştıran nedenlerdendir. Bu karmaşık anatomik sistem, batın bölgesi organlarının hassas analizi ve üç boyutlu görüntülenmesi öncesinde karmaşık ve uyarlamalı bir bölütleme yordamı kullanılmasını zorunlu kılar. Bu çalışmada, yukarıda belirtilen zorlukları aşmak amacıyla, başarımı hassas ölçümlerin yapılabilmesine izin verecek kadar yüksek, batın bölgesi organlarının bölütlemesindeki zorluklarla başa çıkabilecek düzeyde gürbüz ve olası anatomik ve patolojik değişikliklere karşı uyarlamalı bir bölütleme yöntemi geliştirilmiştir.

Geliştirilen bölütleme yöntemi, tasarlanan Çok Aşamalı Hiyerarşik Sınıflayıcı Modelini (ÇAHS) kapsamında her aşamada bir organı bölütler. Sınıflanması kolay olan organdan başlamak suretiyle sınıflanması kolay organ verilerini görece basit ama veri kümesinin tamamında yanlış sınıflama yüzdesi düşük öznitelik-sınıflayıcı çiftleri ile sınıflar. Daha karmaşık öznitelik-sınıflayıcı çiftlerini yalnızca sınıflanması zor organa ait örneklerin sınıflamasında kullanarak, hiyerarşik olarak daraltılmış veri kümesinde yanlış sınıflama hatası düşük olarak bölütleme gerçekleştirir. ÇAHS modelinde her aşamanın çıkışı, bir sonraki aşamanın girişini, yalnızca önceki aşamada geri çevrilen veri ile besleyerek karmaşık öznitelik-sınıflayıcı çiftleri aşamalarında işlenecek veri sayısını azaltan yeni ve özgün bir sınıflama modeli geliştirilmiştir.

Geliştirilen sistemin farklı MR sekansları ile elde edilen batın bölgesi görüntülerine uygulanması sonucunda, batın bölgesinde yer alan, karaciğer, böbrekler, ve dalak gibi organların MR görüntüleri kullanılarak ileri seviye tıbbi analizi ve üç boyutlu incelenmesi gibi pek çok tıbbi prosedür için uygun hassasiyete sahip bir bölütleme başarımı elde edilmiştir.

\section{TEŞEKKÜR (ACKNOWLEDGEMENT)}

$\mathrm{Bu}$ yayın kapsamında geliştirilen tüm çalışmalar Türkiye Bilimsel ve Teknolojik Araştırma Kurumu (TÜBİTAK) tarafindan Elektrik, Elektronik ve Enformatik Araştırma Destek Grubu (EEEAG) 112E032 nolu proje ile desteklenmiştir.

\section{KAYNAKLAR (REFERENCES)}

1. Wu, J., Kamath, MV., Noseworthy, MD., Boylan, C. ve Poehlman, S., "Segmentation of images of abdominal organs." Crit Rev Biomed Eng, Cilt 36, No 5-6, 105-334, 2008.

2. Wang, H., Bai, J., Zhou, Y. ve Zhang, Y., "Abdominal atlas mapping in CT and MR volume images using a normalized abdominal 
coordinate system." Comput Med Imaging Graph, Cilt 32, No 6, 442-451, 2008.

3. Zhou, Y. ve Bai, J. "Multiple abdominal organ segmentation: an atlas-based fuzzy connectedness approach." IEEE Trans Inf Technol Biomed, Cilt 11, No 3, 348-352 2007.

4. Park, H., Bland, P.H. ve Meyer, C.R., "Construction of an abdominal probabilistic atlas and its application in segmentation", Medical Imaging, IEEE Transactions on , Cilt 22, No 4, 483-492, 2003.

5. Koss, J.E., Newman, F.D., Johnson, T.K. ve Kirch, D.L., "Abdominal organ segmentation using texture transforms and a Hopfield neural network", Medical Imaging, IEEE Transactions on, Cilt 18, No 7, 640-648, 1999

6. Campadelli, P., Casiraghi, E., Pratissoli, S. ve Lombardi, G., "Automatic abdominal organ segmentation from ct images", Electronic Letters on Computer Vision and Image Analysis, Cilt 8, 1-14, 2009.

7. Sakashita, M., Kitasaka, T., Mori, K., Suenaga, Y. ve Nawano, S., "A method for extracting multiorgan from four-phase contrasted ct images based on ct value distribution estimation using em-algorithm", Progress in biomedical optics and imaging, Cilt 8, No 1, 1-12, 2007.

8. Linguraru, M. ve Summers, R., "Multi-organ automatic segmentation in $4 \mathrm{~d}$ contrast-enhanced abdominal ct", Biomedical Imaging: From Nano to Macro, 2008. ISBI 2008. 5th IEEE International Symposium on, $45-48,2008$.

9. Selver, M. A., "Segmentation of Abdominal Organs from CT using a Multi-Level, Hierarchical Neural Network Strategy", Computer Methods and Programs in Biomedicine, Cilt 113, 830-852, 2014.

10. Yuan, Z., Wang, Y., Yang J. ve Liu, Y., , "A novel automatic liver segmentation technique for MR images", Image and Signal Processing (CISP), 2010 3rd International Congress on , Cilt 3, No, 1282-1286, 2010.

11. Rafiee, A., Masoumi, H. ve Roosta, A., "Using neural network for liver detection in abdominal MRI images", Signal and Image Processing Applications (ICSIPA), 2009 IEEE International Conference on , Cilt , No , 21-26, 2009

12. Rajasvaran, L., Haw, T.W. ve Sarker, S.Z., "Liver isolation in abdominal MRI", Journal of Medical Systems, Cilt 32, No 4, 259-268 2008.

13. Akyar, H., Selver, M.A. ve Demir, G.K., "Segmentation and registration of kidneys from contrast enhanced abdominal MR image", Signal Processing, Communication and Applications Conference, SIU 2008, IEEE 16th, Aydın, 1-4, 2008

14. Behrad, A.; Masoumi, H.; , "Automatic spleen segmentation in MRI images using a combined neural network and recursive watershed transform", Neural Network Applications in Electrical Engineering (NEUREL), 10th Symp., pp.63-67, Sept. 2010.

15. Barra, V. ve Boire, J.Y., "Segmentation of fat and muscle from MR images of the thigh by a possibilistic clustering algorithm", Computer Methods and Programs in Biomedicine, Cilt 68, No 3, 185- 1932002.

16. Terry, J. B., Weymouth, T. E., ve Meyer, C. R., "Multiple organ definition in ct using a bayesian approach for 3d model fitting", Vision Geometry IV, Proc. SPIE, 244-251 1995.

17. de Bruijne, M. et al, "Automated Segmentation of Abdominal Aortic Aneurysms in Multi-spectral MR Images", Medical Image Computing and Computer-Assisted Intervention MICCAI 2003, Montreal, Canada, 2003.

18. Zhuge, F., Rubin, G. D. ve Sun, S., "An abdominal aortic aneurysm segmentation method: Level set with region and statistical information", Napel Med. Phys. Cilt 33, 2006

19. Lapeer, R. J., Tan, A. C. ve Aldridge, R., "Active Watersheds: Combining 3D Watershed Segmentation and Active Contours to Extract Abdominal Organs from MR Images", MICCAI 2002, Tokyo Japan, 2002.

20. Ballard, D., Shani, U. ve Schudy, R., "Anatomical models for medical images", Computer Software and Applications Conference, 1979. Proceedings. COMPSAC 79. The IEEE Computer Society's Third International, 1979.

21. Karssemeijer, N., "A statistical method for automatic labeling of tissues in medical images", Machine Vision and Applications, Cilt 3, 7586, 1990.

22. Zhou, Y., ve Bai, J., "Multiple abdominal organ segmentation: An atlas-based fuzzy connectedness approach", Information Technology in Biomedicine, IEEE Transactions on, Cilt 11, No 3, 348 -352, 2007.

23. Park, H., Bland, P., ve Meyer, C., "Construction of an abdominal probabilistic atlas and its application in segmentation", Medical Imaging, IEEE Transactions on, Cilt 22, No 4, $483-492$, 2003.

24. Kobashi, M. ve Shapiro, L.G. "Knowledge-based organ identification from ct images", Pattern Recognition, Cilt 28, No 4, 475 - 491, 1995.

25. Yoo, S. W., Cho, J.-S., Noh, S.-M., Shin, K.-S. ve Park, J.-W., "Organ segmentation by comparing of gray value portion on abdominal CT image", Signal Processing Proceedings, 2000. WCCC-ICSP 2000. 5th International Conference on, vol.2, no., pp.1201,1208 vol.2, 2000

26. Gu, L. ve Kaneko, T., "Organs extraction using three-dimensional mathematical morphology", Signal Processing Proceedings, 1998. ICSP '98. 
1998 Fourth International Conference on, 1998.

27. Bae, K. T., Giger, M. L., Chen, C. T. ve Kahn, C. E., "Automatic segmentation of liver structure in CT images." Medical physics, Cilt 20, No 1, 7178,1993

28. Koss, J., Newman F., Johnson, T. ve Kirch, D., "Abdominal organ segmentation using texture transforms and a hopfield neural network", Medical Imaging, IEEE Transactions on, Cilt 18, No 7, 640-648, 1999.

29. Kurani, A., Xu, D., Furst, J. ve Raicu, D., "Cooccurrence matrices for volumetric data", The Seventh IASTED International Conference on Computer Graphics and Imaging CGIM 2004, K. M. Hanson, Ed., 426-443, 2004,.

30. Ciurte A. ve Nedevschi, S., "Texture analysis within contrast enhanced abdominal ct images", Intelligent Computer Communication and Processing, 2009. ICCP 2009. IEEE 5th International Conference on, 73-78, 2009.

31. Selfridge, P., Judith, M., Prewitt, M., Dyer, C. ve Ranade S., "Segmentation algorithms for abdominal computerized tomography scans", Computer Software and Applications Conference, Proc. IEEE Computer Society's 3rd Intern., 1979.

32. $\mathrm{Wu}$, J., Poehlman, S. , Noseworthy, M. ve Kamath, M., "Texture feature based automated seeded region growing in abdominal mri segmentation", BioMedical Engineering and Informatics, 2008. BMEI 2008. International Conference on, Cilt 2, $263-267,2008$.

33. Campadelli, P., Casiraghi E. ve Pratissoli, S., "Fully automatic segmentation of abdominal organs from ct images using fast marching methods", Computer-Based Medical Systems, CBMS, $21^{\text {st }}$ IEEE International Symposium, pp. $554-559,2008$.

34. Jiang, $H$. ve Cheng, Q., "Automatic 3d segmentation of CT images based on active contour models", Computer-Aided Design and Computer Graphics, 2009. CAD/Graphics '09. 11th IEEE International Conference on, pp. $540-543,2009$.

35. Siegel, E. L., Kolodner, R. M., (Eds.), Filmless Radiology, 1st ed., Springer, 1999.

36. Haacke, E. M., et al. "Magnetic resonance imaging." Physical principles and sequence design , 1999.

37. Lai, C.-C. ve Chang, C.-Y., "A hierarchical evolutionary algorithm for automatic medical image segmentation", Expert Systems with Applications, Cilt 36, No 1, 248-259, 2009.

38. Husain, S.A., ve Shigeru, E., "Use of neural networks for feature based recognition of liver region on ct images", Neural Networks for Signal Processing X, 2000. Proc. of the 2000 IEEE Signal Processing Society Workshop, Sydney, NSW 2000.
39. Chang, C.-Y. ve Chung, P.-C., "Medical image segmentation using a contextual-constraint-based hopfield neural cube", Image and Vision Computing, Cilt 19, No 9-10, 669-678, 2001.

40. Lee, C.-C., Chung, P.-C. ve Tsai, H.-M., "Identifying multiple abdominal organs from ct image series using a multimodule contextual neural network and spatial fuzzy rules", Information Tech. in Biomd, IEEE Trans. on, Cilt 7, No 3, 208 -217, 2003.

41. Chen, K. ve Chi, H., "A method of combining multiple probabilistic classifiers through soft competition on different feature sets", Neurocomputing, Cilt 20, 227-252, 1998.

42. Kittler, J., Hatef, M., Duin, M. ve Matas, J., “On combining classifiers", IEEE Trans. Pattern Anal. Mach. Intell., Cilt 20, No 3, 226 -239, 1998.

43. Ho, T. K., Hull J. J. ve Srihari S. N., "Decision combination in multiple classifier systems", IEEE Trans. Pattern Anal. Mach. Intell., Cilt 16, 66-75, 1994.

44. Cao, J., Shridhar, M. ve Ahmadi, M., "Fusion of classifiers with fuzzy integrals", in Document Analysis and Recognition, 1995., Proceedings of the Third International Conference on, Cilt 1, 108-111 1995.

45. Chen, K., "On the use of different speech representations for speaker modeling”, Systems, Man, and Cybernetics, Part C: Applications and Reviews, IEEE Trans. on, Cilt 35, No 3, 301-314, 2005.

46. Chen, K., Wang, L. ve Chi, H., "Methods of combining multiple classifiers with different features and their applications to text-independent speaker identification" Int. Jour. Pattern Recognition and Artificial Intelligence, Cilt 11, 417-445, 1997.

47. Xu, L., Krzyzak, A. ve Suen , C., "Methods of combining multiple classifiers and their applications to handwriting recognition", Systems, Man and Cybernetics, IEEE Transactions on, Cilt 22, No 3, 418 -435, 1992.

48. Suen, C. Y., Legault, R., Nadal, C., Cheriet, M. ve Lam, L., "Building a new generation of handwriting recognition systems", Pattern Recogn. Letters, Cilt 14, 303-315, 1993.

49. Huang, Y. S. ve Suen, C. Y., "A method of combining multiple experts for the recognition of unconstrained handwritten numerals", IEEE Trans. Pattern Anal. Mach. Intell., Cilt 17, 9094, January 1995.

50. Selver, M. A., Akay O., Alim F., Bardakçı, S. ve Ölmez, M., "An automated industrial conveyor belt system using image processing and hierarchical clustering for classifying marble slabs", Robotics and Computer-Integrated Manufacturing, Cilt 27, No 1, 164 - 176, 2011.

51. Unser, M., 'Sum and difference histograms for texture classification,' IEEE Trans. Pattern 
Anal. Mach. Intell., Cilt PAMI-8, No 1, 118 $125,1986$.

52. Selver, M. A., Kocaoğlu, A., Demir, G., Doğan, H., Dicle ve O., Güzeliş, C ., "Patient oriented and robust automatic liver segmentation for preevaluation of liver transplantation", Computers in Biology and Medicine, Cilt 38, No7, 765-784, 2008.

53. Selver, M.A., Kocaoglu, A., Akyar, H., Dicle, O., ve Guzelis, C., "Patient oriented neural networks to overcome challenges of abdominal organ segmentation in CT angiography studies", ELECO, International Conf. on, pp.II-177-181, Nov 2009.

54. Haykin, S., Neural Networks: A Comprehensive Foundation, Prentice Hall, 2. bask1, 1998.

55. Reed, R., Marks, R. J.: Neural Smithing: SupervisedLearning in Feed forward Artificial Neural Networks, MIT Press, 1999. 